Revista lus et Praxis, Año 17, № 1, 2011, pp. 57 - 80

ISSN 0717 - 2877

Universidad de Talca - Facultad de Ciencias Jurídicas y Sociales

"Artículo 915 del Código Civil: una solución jurisprudencial a la limitación de las acciones tradicionales"

Arturo Selman Nahum

\title{
ARTÍCULO 915 DEL CÓDIGO CIVIL: UNA SOLUCIÓN JURISPRUDENCIAL A LA LIMITACIÓN DE LAS ACCIONES TRADICIONALES*
}

\author{
ARTICLE 915 OF THE CIVIL CODE: A JURISPRUDENTIAL SOLUTION TO THE \\ LIMITATION OF THE TRADITIONAL ACTIONS
}

\begin{abstract}
Arturo Selman Nahum ${ }^{*}$
RESUMEN

La doctrina y jurisprudencia chilena ha expuesto a través del tiempo variados argumentos tendientes a afirmar que, del artículo 915 del Código Civil, emana la acción reivindicatoria contra el mero tenedor y simple detentador. Debido a la discordancia de tales argumentos con algunos artículos del Código Civil, resulta necesario dilucidar si efectivamente se trata de una acción legítima y con sustentos legales o más bien, viene a amparar situaciones injustas que no tienen una solución efectiva mediante las acciones tradicionales.

ABSTRACT

THE DOCTRINE AND CHILEAN JURISPRUDENCE HAS EXPOSED THROUGH THE TIME VARIED ARGUMENTS TENDING TO AFFIRM THAT, OF THE ARTICLE 915 OF THE CIVIL CODE, EMANATES THE ACTION CLAIMING AGAINST THE MERE HOLDER AND SIMPLE DETAINER. DUE TO THE DISCORD OF SUCH ARGUMENTS WITH SOME ARTICLES OF THE CIVIL CODE, IT IS NECESSARY CLARIFY IF REALLY IS A LEGITIMATE ACTION WITH LIVELIHOODS LEGAL OR RATHER COMES TO PROTECT UNFAIR SITUATIONS THAT DO NOT HAVE AN EFFECTIVE SOLUTION THROUGH THE TRADITIONAL ACTIONS.

\section{Palabras Clave}

Injusto Detentador, Poseedor a Nombre Ajeno, Artículo 915 del Código Civil

KEY WORDS

Unjust Detainer, Possessor to Another Name, Article 915 of the Civil Code
\end{abstract}

\section{INTRODUCCIÓN}

En la actualidad, el artículo 915 del Código Civil (en adelante Art. 915 CC) goza de una variada interpretación jurisprudencial, la cual tiende a clasificarlo como una acción reivindicatoria excepcional, que limita la necesidad de posesión del reivindicado en los términos que exige el Código Civil, permitiendo que dicha acción se interponga contra un mero tenedor y simple detentador.

\footnotetext{
*Trabajo recibido el 5 de octubre de 2010 y aprobado el 11 de enero de 2011.

** Licenciado en Ciencias Jurídicas y Sociales, Universidad Diego Portales; Abogado. Correo electrónico: arturo.selman@gmail.com.
} 
Resulta importante destacar que se explicará la discusión del Art. 915 CC en relación con los inmuebles, mas no con los muebles, debido a que las soluciones aplicables resultan extensibles a ambos respectos ${ }^{1}$, siendo redundante tratarlos por separado. Además, respecto de los inmuebles sujetos a inscripción, se presenta el inconveniente adicional de la obligatoriedad de inscripción registral para obtener y perder la posesión respectivamente, situación que no se encuentra presente en los muebles y por tanto fuera de discusión.

En cuanto a la estructura formal del presente trabajo, su orden es el siguiente: en el capítulo primero, titulado "acción reivindicatoria", se expondrán someramente sus aspectos generales. En el capítulo segundo, se realizará un análisis crítico de las diferentes posturas adoptadas por la doctrina y jurisprudencia respecto de la acción que emana del Art. 915 CC. En el capítulo tercero, se desarrollarán los distintos estados en que un individuo puede estar frente a una cosa, para luego explicar en el capítulo cuarto, las consecuencias que puede aparejar la negación de la acción contra el injusto detentador. En el capítulo quinto, titulado "casos prácticos", se determinará en qué situaciones resulta justificable utilizar dicha acción como una salida alternativa a la ineficacia de las demás acciones que otorga el Código Civil. Finalmente, en el apartado de la conclusión, se recapitulará sobre lo planteado y se resaltarán las ideas principales del texto.

Es menester aclarar que al tratarse de una materia que ha tenido una mayor discusión a nivel jurisprudencial, las teorías analizadas no son las únicas existentes y es posible encontrar más hipótesis de las aquí tratadas, aunque se procuró utilizar las que tienen mayor sustento en la jurisprudencia y desarrollo en la doctrina.

\section{AcCIÓN ReIVINDICATORIA}

La reivindicación o acción de dominio se encuentra regulada en el Título XII del Libro II del Código Civil. El Art. 889 CC la define como “...la que tiene el dueño de una cosa singular, de que no está en posesión, para que el poseedor de ella sea condenado a restituírsela". Es una acción real, cuyo principal objetivo es la protección de los derechos reales (Art. 577 CC). En este sentido, Francesco Messineo sostuvo que su fundamento principal es el poder de persecución y la inherencia del derecho a la cosa, propios de todo derecho real ${ }^{2}$.

En lo que respecta a los requisitos de la acción reivindicatoria, ellos se desprenden de su propia definición y son los siguientes, a saber: A. Que se trate

\footnotetext{
${ }^{1}$ Salvo ciertos matices que se explicarán en su oportunidad.

2 Alessandri Rodríguez, Arturo; Somarriva Undurraga, Manuel, Los Bienes y Los Derechos Reales, Editorial Nascimento, Santiago, 1974, p. 799, citando a su vez a Messineo, Francesco, Diritto Civile e Comerciale, Vol. II., Giuffre, Milán, 1947, p. 106.
} 
de una cosa susceptible de ser reivindicada; B. Que el reivindicante sea dueño de ella, y C. Que el reivindicante esté privado de su posesión ${ }^{3}$. El contenido y explicación de los requisitos no merece mayor comentario en cuanto las normas del Código Civil lo tratan detalladamente.

El Art. 915 CC es el último precepto que se refiere a la acción reivindicatoria, resultando paradójicamente poco conciliador en relación con las normas que lo anteceden, sembrando dudas acerca de su aplicación y naturaleza jurídica. Es importante recordar los requisitos de la acción reivindicatoria, debido a que los tribunales de justicia han interpretado el Art. 915 CC de una manera muy peculiar, entendiéndolo como una acción reivindicatoria, pero obviando a su vez la obligatoriedad de que el reivindicante se encuentre privado de la posesión de la cosa.

\section{Análisis y teorías del artículo 915 del Código Civil}

El objetivo de este capítulo es transparentar el significado real del Art. 915 CC, por ello resulta necesario analizar detalladamente su contenido, para determinar de qué manera se ha llegado a sostener que de dicho precepto se desprende una acción diversa a la reivindicatoria o un tipo excepcional de ella, en contra del mero tenedor y simple detentador. El Art. 915 CC señala: "Las reglas de este título se aplicarán contra el que poseyendo a nombre ajeno retenga indebidamente una cosa raíz o mueble, aunque lo haga sin ánimo de señor".

A todas luces, este artículo presenta una frase que sobresale al resto y en virtud de la cual se ha llegado a diferentes conclusiones. La noción "poseyendo a nombre ajeno", ha sido objeto de diversas interpretaciones de las que ha resultado una serie de teorías. A modo introductorio, cabe señalar que la mayoría de la jurisprudencia lo ha asimilado a la situación del mero tenedor, lo cual amplía ostensiblemente su ámbito de aplicación. En este sentido, la Corte Suprema en sentencia de 12 de mayo de 1992 sostuvo en su considerando 9०: "Que, como se ha resuelto por esta Corte, el artículo 915 del Código Civil consagra una excepción a las reglas establecidas respecto de contra quién se puede dirigir la acción reivindicatoria, esto, porque permite ejercerla, no en contra de un poseedor, sino en contra de un mero tenedor ${ }^{\prime \prime 4}$. Esta interpretación

\footnotetext{
${ }_{3}^{3}$ Peñallillo Arévalo, Daniel, Los Bienes, La Propiedad y otros Derechos Reales, Editorial Jurídica de Chile, Santiago, 2006, p. 516.

${ }^{4}$ Sentencia de la Excma. Corte Suprema, rechaza recurso de casación en el fondo interpuesto en contra de la resolución del tribunal a quo que acogió la acción reivindicatoria en contra de un mero tenedor, 12 de mayo de 1992. En: http://www.microjuris.cl [visitado el 04/10/2010], № de Identificador Documento: RDJ1569.
} 
ha sido sostenida durante el último tiempo, pero no ha logrado argumentar de manera sólida el porqué de dicha aseveración.

Dilucidada la noción del Art. 915 CC que genera conflicto, resulta procedente explicar las diversas teorías que existen a su respecto. En efecto, de una lectura detallada del citado artículo se desprenden varias posturas, a saber:

A. Procede la acción reivindicatoria contra el injusto detentador ${ }^{5}$ (entendido como mero tenedor y/o simple detentador) que retenga indebidamente una cosa;

B. Procede una acción personal o restitutoria especial (según corresponda) contra el mero tenedor que retenga indebidamente una cosa, que hacen extensible las normas relativas a las prestaciones mutuas, y

C. Las reglas del Título XII del Libro II del Código Civil se aplican contra el poseedor a nombre ajeno que retenga indebidamente una cosa, siempre que aquél se entienda en conformidad a lo dispuesto en los artículos 719 inciso $2^{\circ}$, 720 y 721 CC.

La primera teoría es la más utilizada por nuestra jurisprudencia en la actualidad $^{6}$, e incluso se ha dado por supuesto que dicho artículo se aplica sin más, frente a una persona que no es poseedora propiamente tal de un inmueble ${ }^{7}$ pero que lo detenta materialmente. En esta línea, la Corte Suprema en sentencia de fecha 23 de abril de 2007 dictaminó: "En consecuencia, debe afirmarse que, si bien por definición la acción reivindicatoria se confiere al dueño de la cosa que es poseída por otro, entendiendo el concepto posesión

\footnotetext{
${ }^{5}$ No existe consenso respecto del contenido de la noción injusto detentador. Algunos estiman que sólo se refiere a quienes nunca han tenido un título justificativo de tenencia, dejando fuera al mero tenedor que expirado su título, se niega a restituir la cosa. Otros en cambio, estiman que en ambos casos se trataría de un injusto detentador. Se adhiere a esta última postura, por cuanto un mero tenedor que al momento de la demanda no puede justificar la tenencia de la cosa, es un injusto detentador. En apoyo a esta postura, el Art. 1949 CC -único artículo en el Código Civil que se refiere a esta noción- lo asimila al mero tenedor (arrendatario) que se niega a restituir la cosa. Se debe dejar claro que la noción injusto detentador es un concepto amplio y abierto que no se relaciona necesariamente con el Art. 915 CC, ya que existen variadas situaciones en que el infractor se denomina injusto detentador, pero ello no significa que se circunscriban en el ámbito de aplicación del artículo en comento.

${ }^{6}$ Anteriormente primó en doctrina la segunda teoría, en su favor Claro SOLAR, Luis, Explicaciones de Derecho Civil Chileno y Comparado Tomo IX, Editorial Nascimiento, Santiago, 1935, p. 458 y Veloso Chávez, Alberto, La Reivindicación, Memoria de Prueba, Santiago, № 1804, 1947, № 44, pp. 34-35.

7 Ello, en razón de los artículos 724 y 728 CC, que exigen la inscripción conservatoria para adquirir la posesión, en relación con los artículos 889 y 895 del mismo cuerpo legal, que ordenan que la acción reivindicatoria se ejerza en contra del actual poseedor. Cabe destacar que lo anterior, se refiere a los inmuebles que han ingresado al sistema registral; además, la posesión también se puede perder por un decreto judicial que cancele la inscripción.
} 
en los términos del inciso $1^{\circ} \mathrm{del}$ artículo 700 del Código Civil, la ley también le confiere la acción de dominio al que no ha perdido la posesión de la cosa, pues mantiene al menos el animus propio del poseedor, pero sí ha perdido su tenencia material, la que es detentada por otro que, aun cuando reconoce dominio ajeno, la conserva indebidamente ${ }^{\prime 8}$. En este mismo sentido, la Corte de Apelaciones de San Miguel con fecha 25 de septiembre de 2009 dispuso: "Que de acuerdo a las normas legales antes citadas y a fin de seguir el razonamiento, cabe agregar que el artículo 895 del Código sustantivo preceptúa que la acción de dominio se dirige en contra del actual poseedor, sin perjuicio que el artículo 915 del Código Civil autoriza en forma expresa la acción reivindicatoria contra la persona que tiene la tenencia de la cosa raíz o mueble, sin que sea necesario para que prospere la acción que sea poseedora de ella, es decir, la ley permite ejercer esta acción tanto contra el poseedor como contra el mero tenedor que la retenga indebidamente y aunque lo haga sin ánimo de señor y dueño"s.

La Corte Suprema, al realizar estas aseveraciones, denota el olvido de normas fundamentales del Código Civil, tales como los artículos 724, 728, 889 y 895 , todos los cuales no hacen más que contradecir este tipo de razonamiento. Su principal fundamento pareciera no ser jurídico, sino más bien nace de la urgencia de resolver problemáticas que no encuentran una solución admisible frente a determinadas situaciones de hecho que resultan injustas, como sería el caso de un promitente vendedor que entrega un inmueble antes de suscribir el contrato prometido y este último nunca se llega a celebrar. Frente a una situación así, resulta de suma utilidad esta interpretación ya que permite accionar en contra del injusto detentador posibilitando la recuperación del bien raíz.

Arturo Alessandri Rodríguez, en concordancia con esta teoría, concluye: "... la acción reivindicatoria procede, de acuerdo con el Art. 915, contra el injusto detentador. Puede suceder que un mero tenedor de la cosa o un simple detentador, se quede con ella o se niegue a restituirla; llegado el caso la ley permite entonces que se pueda ejecutar en su contra la acción reivindicatoria. El pro-

\footnotetext{
${ }^{8}$ Sentencia de la Excma. Corte Suprema, acoge recurso de casación en el fondo interpuesto en contra de la resolución del tribunal a quo que rechazó la acción reivindicatoria, 23 de abril de 2007. En: http://www.microjuris.cl [visitado el 04/10/2010], Nº de Identificador Documento: MJJ9696.

${ }^{9}$ Sentencia de la Iltma. Corte de Apelaciones de San Miguel, rechaza el recurso de casación en la forma interpuesto en contra de la resolución del tribunal a quo que rechazó la acción reivindicatoria, toda vez que el demandante no acreditó que el retazo que se pretendía reivindicar haya estado ocupado por el demandado. Sin perjuicio de ello, la Corte reconoció que el Art. 915 CC faculta para demandar en contra de toda persona que detente la tenencia material de una cosa corporal inmueble, 25 de septiembre de 2009. En: http://www.microjuris.cl [visitado el 04/10/2010], $N^{\circ}$ de Identificador Documento: MJJ21876.
} 
pietario pues puede optar entre la acción personal proveniente del contrato en cuya virtud el tenedor detenta la cosa y la acción reivindicatoria"no.

Otro de sus sustentos, es la teoría de la posesión material, la cual expone que al privar injustamente al dueño de la tenencia física de la cosa raíz, se vulnera su posesión y por ende se vería privado "de una parte integrante de la posesión"111. La Corte Suprema, apoyando esta tesis, sentenció: "Dentro del sistema del Código Civil sobre el dominio y la posesión inscrita de los bienes raíces, no cabe duda de que el dueño y poseedor inscrito de un inmueble tiene aptitud jurídica para ejercitar la acción reivindicatoria en contra de quien detenta su posesión material. Por consiguiente, constituye un error de derecho sostener que la acción reivindicatoria, tratándose de bienes raíces, es improcedente contra el poseedor material (sentencias de 21 de septiembre de 1955 y de 7 de marzo de 1961, Revista de Derecho y Jurisprudencia, tomos 52 y 58, sección 1a, páginas 294 y 23, respectivamente)"12.

Gracias a este planteamiento se ha sostenido que el injusto detentador afecta la posesión material del dueño y por tanto, es aplicable en su contra la acción reivindicatoria sin contradecir los artículos 889 y 895 CC. Lamentablemente, dicha teoría no tiene fundamento alguno en nuestro Código Civil; en su rechazo los artículos 724 y 728 CC refuerzan la idea de que sólo se puede perder la posesión de un bien raíz inscrito mediante su cancelación, sea por voluntad de las partes o por una nueva inscripción en el Conservador de Bienes Raíces hecha por el poseedor inscrito, o por decreto judicial, por tanto la afectación material no altera la posesión inscrita.

La segunda teoría, postula que el Art. 915 CC, "sólo hace aplicables las reglas sobre prestaciones mutuas, establecidas en el párrafo IV del Título XII del Libro II del Código Civil, contra el mero tenedor que no es poseedor, pero no le otorga la correspondiente acción en el carácter de reivindicatoria, en razón de que el poseedor inscrito conserva la posesión de la cosa y el tenedor de ella no tiene el ánimo de señor, aunque resista injustamente la entrega (en tal sentido, CLARO SOlar, Luis, en su Tratado de Derecho Civil, T. IX, ed. de 1.935, N.1804, página

\footnotetext{
${ }^{10}$ Alessandri Rodríguez, Arturo, De los Bienes, versiones taquigráficas tomadas en la clase del señor Arturo Alessandri Rodríguez por Onias León Gaete, Editorial Zamorano y Caperan, Santiago, 1937, p. 211. Cabe mencionar que el autor con posterioridad se inclina por la segunda teoría (ALESSANDRI ROdríguez, Arturo; Somarriva Undurraga, Manuel, Curso de Derecho Civil, Tomo II, Editorial Nascimento, Santiago, 1957, pp. 811-814).

${ }^{11}$ Peñallillo, Los Bienes, cit. nota n. 3, p. 531.

${ }^{12}$ Sentencia de la Excma. Corte Suprema, rechaza recurso de casación en el fondo interpuesto en contra de la resolución del tribunal a quo que rechazó la acción reivindicatoria. Pese a ello, la Corte Suprema hizo hincapié en la procedencia de la acción reivindicatoria en contra del poseedor material, 27 de diciembre de 2004. En: http://www.microjuris.cl [visitado el 04/10/2010], № de Identificador Documento: MJJ9149.
} 
458, y Veloso Chávez, Alberto: La Reivindicación, Memoria de Prueba, Santiago, 1947, páginas 34-35)"133. En la misma opinión Fernando Rozas Vial, quien estima: "...poseer a nombre ajeno no significa ser mero tenedor de una cosa. La mera tenencia requiere que se reconozca dominio ajeno y es incompatible con la posesión, nosotros pensamos que el Art. 915 sólo establece que cuando se recupera la cosa del mero tenedor, se aplican las reglas de la reivindicación relativas a las prestaciones mutuas (frutos, expensas, deterioros, etc.)"114.

Esta teoría a su vez, tiene dos ámbitos de aplicación: A. El primer ámbito supone que exista una relación contractual entre el afectado (dueño de la cosa) y el mero tenedor que retiene indebidamente una cosa, en cuyo caso se debe ejercer la acción personal que corresponda, haciendo extensible las reglas sobre las prestaciones mutuas. En otras palabras, se aplica como anexo a la acción personal respectiva. B. El segundo ámbito plantea una acción restitutoria especial $^{15}$, a la que también se hacen extensibles las reglas relativas a las prestaciones mutuas. Este planteamiento parece acercarse más a la lógica impuesta en los artículos 724 y 728 CC, en relación con el carácter absoluto de la inscripción registral, al reconocer la improcedencia de la acción reivindicatoria contra el mero tenedor. Lamentablemente, no se hace cargo respecto del fundamento de dicha acción, como tampoco de la situación en que el poseedor a nombre ajeno retenga la cosa con ánimo de señor o dueño ${ }^{16}$. En la actualidad, esta postura ha tenido poca acogida y discusión jurisprudencial, razón por la cual no se ahondará mayormente en ella.

La tercera teoría ${ }^{17}$ es el resultado de una interpretación armónica con las demás normas del Código Civil. Postula, tal y como señala el tenor literal del Art. 915 CC, que un sujeto que posee a nombre ajeno y retiene indebidamente una cosa, puede ser objeto de las reglas del Título XII de Libro II del Código Civil, siempre que se restrinja esta noción a lo dispuesto en los artículos 719 inciso $2^{\circ}, 720$ y 721 del CC, esto es, aquél que ha empezado a poseer a nombre ajeno como mandatario, representante legal o agente oficioso.

\footnotetext{
${ }^{13}$ Sentencia de la Iltma. Corte de Apelaciones de Santiago, rechaza recurso de apelación interpuesto en contra de la resolución del tribunal a quo que rechazó la acción reivindicatoria en contra de la persona que detenta materialmente una cosa corporal inmueble, 11 de agosto de 2003. En: http://www. poderjudicial.cl [visitado el 04/10/2010], Rol № 7892-1998.

${ }^{14}$ Rozas Vial, Fernando, Los Bienes, Editorial LexisNexis, Santiago, 2006, p. 375.

${ }^{15}$ En caso que aquél que retiene indebidamente una cosa, lo haga en virtud de un contrato o relación jurídica suscrito con un tercero distinto al dueño.

${ }^{16}$ Situación perfectamente posible de acuerdo al sentido natural y obvio de la lectura del Art. 915 CC. Al señalar: "aunque lo haga sin ánimo de señor" da por entendido la posibilidad en sentido inverso.

17 Propuesta por Barrientos Grandón, Javier, "De los Bienes y de su Dominio, Posesión, Uso y Goce", Revista Chilena de Derecho Privado N 4, 2005, pp. 241 y ss.
} 
El problema de este raciocinio es que restringe en demasía el contenido del Art. 915 CC. En efecto, los artículos 719 inciso $2^{\circ}, 720$ y 721 CC, hacen alusión a la "posesión a nombre ajeno", y si el precepto discutido se refiriere sólo a aquellos casos, sería de escasa utilización. En esta línea argumental, Javier Barrientos Grandón señala: "el poseedor a nombre ajeno" en el Derecho Civil chileno corresponde a una categoría técnica muy precisa y restringida, de un concreto detentor que tiene la calidad de representante legal, mandatario o agente oficioso ex artículo 721 CC de aquél respecto de quien se posee"118. En línea similar ${ }^{19}$, la Corte de Apelaciones de Temuco en sentencia del 24 de agosto de 2005 en su considerando $17^{\circ}$ estableció: "es posible concluir que el artículo 915 comentado, norma excepcional en cuanto a señalar un sujeto pasivo de la acción reivindicatoria, está reservado solamente a la situación que se produce cuando el mero tenedor tiene la cosa a nombre ajeno y ese "ajeno es el verdadero propietario" 20 .

La referida sentencia amplía la expresión poseyendo a nombre ajeno a mero tenedor, pero con la salvedad que tenga la cosa a nombre del propietario; es decir, se restringe la concepción de mero tenedor a situaciones determinadas como la que se presenta en un contrato de comodato, toda vez que el comodatario no restituya la cosa y por alguna razón no prospere la acción personal ${ }^{21}$ o inclusive si el comodante elige accionar primero por el Art. 915 CC en vez de la acción personal22.

Si bien la interpretación de la Corte de Apelaciones de Temuco (confirmada por la Corte Suprema en sentencia del 13 de junio de $2007^{23}$ ) tiende a acercarse más al significado literal del artículo en cuestión, no da razones suficientes para equiparar la expresión poseyendo a nombre ajeno con mero tenedor que tiene la cosa a nombre del propietario. Es menester destacar que la sola expresión poseyendo a nombre ajeno genera más de una interrogante. A primera vista se podría relacionar con la parte final del Art. 700 CC, que establece: "la posesión es la tenencia de una cosa determinada con ánimo de señor o dueño, sea que

\footnotetext{
${ }^{18}$ Barkientos Grandón, Javier, "De los Bienes y de su Dominio, Posesión, Uso y Goce: Poseedor a Nombre Ajeno", Revista Chilena de Derecho Privado No 8, 2007, p. 277.

${ }^{19}$ Se inclina por la teoría de Javier Barrientos Grandón, pero con ciertos matices.

${ }^{20}$ Barrientos, "De los Bienes", cit. nota n. 18, p. 274.

${ }^{21}$ Por ejemplo, una vez prescrita la acción personal que emana del contrato de comodato.

${ }^{22}$ No habría norma que obligase utilizar una antes que otra. Más adelante se explicará la importancia de exigir el agotamiento de la acción personal antes que el ejercicio de la acción contra el injusto detentador.

${ }^{23}$ Sentencia de la Excma. Corte Suprema, rechaza recurso de casación en el fondo interpuesto en contra de la resolución del tribunal a quo que rechazó la acción reivindicatoria, 13 de junio de 2007. En: http://www.poderjudicial.cl [visitado el 04/10/2010], Rol N 5210-2005.
} 
el dueño o el que se da por tal tenga la cosa por sí mismo, o por otra persona que la tenga en lugar y a nombre de él", por lo que se entendería que dicha noción es equiparable a quien tiene una cosa en lugar y a nombre del dueño, es decir, al mero tenedor (Art. 714 CC). Sin embargo, el inciso $2^{\circ}$ del Art. 719 CC viene a dilucidar qué debe entenderse por poseedor a nombre ajeno, reconociendo en aquél una calidad especial, distinta a la del genérico mero tenedor. Lo anterior, relacionado con el Art. 721 CC, resuelve la acertada inteligencia de la noción discutida, toda vez que el citado artículo señala en qué casos se genera esta peculiar situación ${ }^{24}$.

Finalmente, se puede afirmar que la primera y segunda teoría no logran encontrar una justificación legal. En efecto, la primera postura es muy útil, pero entender que existe una acción reivindicatoria contra un mero tenedor va en contra de lo que disponen los artículos 889 y 895 CC. Tampoco justifica el símil que hace de las nociones poseyendo a nombre ajeno con mero tenedor. Por otra parte, la segunda teoría no fundamenta la acción restitutoria que propone. Además, de los contratos celebrados emana la correspondiente acción personal, siendo en la mayoría de las ocasiones suficiente para obtener la restitución de la cosa corporal que se deba. La tercera teoría parece correcta, siempre que se entienda de manera restringida la expresión poseyendo a nombre ajeno (Art. 721 CC) sin asimilarlo a mero tenedor. Ahora, suponiendo que sea la tesis correcta, ¿qué situaciones pueden presentarse ante un caso real?

A efectos de llevar a cabo la explicación, resulta imperante hacer la salvedad que el Art. 896 CC es la regla aplicable contra el mero tenedor, cuyo objetivo es que el sujeto pasivo declare el nombre y residencia de la persona a cuyo nombre tiene la cosa y posteriormente, se ejerza la acción reivindicatoria contra el poseedor que corresponda. Señalado lo anterior, frente a la interrogante planteada, Javier Barrientos Grandón expone: "si alguien (mandatario, representante o quien no tenga tal calidad, después de conocida y aceptada la toma de posesión en los términos del artículo 721) ha comenzado a poseer a nombre ajeno una cosa mueble o raíz la retiene indebidamente, con ánimo de señor o sin él, pueden presentarse las siguientes situaciones ${ }^{\prime \prime 2}$, acto seguido explica que será diferente si aquél para quien poseía ya ha enterado el plazo de prescripción adquisitiva y el poseedor a nombre ajeno retiene indebidamente una cosa sin ánimo de dueño (en cuyo caso se convertiría en un mero tenedor, siendo aplicable en su contra los artículos 896 y 915 CC) o si la retiene con ánimo de dueño (posible únicamente en cosas corporales muebles, procediendo en su contra la acción reivindicatoria por tratarse de un poseedor conforme los términos del Art. 700 CC). Además, se plantea el caso inverso, es decir, si aquél

${ }^{24}$ Casos puntuales, específicamente mediante mandatario, representante legal y agente oficioso.

${ }^{25}$ Barrientos, "De los Bienes", cit. nota n. 17, p. 242. 
para quien poseía no ha enterado el plazo de la prescripción adquisitiva y el poseedor a nombre ajeno retiene indebidamente la cosa con o sin ánimo de señor o dueño. Si bien las alternativas y soluciones aplicables son diversas ${ }^{26}$, se clarifica la correcta interpretación del Art. 896 CC en relación con el Art. 915 del mismo cuerpo legal.

En base a los argumentos expuestos, se puede inferir que esta teoría es la que más se asemeja a la redacción del Art. 915 CC. Entonces, ¿por qué los tribunales de justicia se han inclinado por la primera postura? Existen dos respuestas posibles: A. Se debe a una interpretación equívoca que confunde los conceptos de poseedor y mero tenedor. B. Estamos frente a una interpretación que siendo errónea tiene un objetivo claro, cual es, subsanar un déficit normativo permitiendo la recuperación de una cosa corporal de manos de quien la detenta injustamente. No resulta aventurado inclinarse por la última respuesta, por cuanto los tribunales de justicia han planteado a través del tiempo una serie de argumentos tendientes a justificar la acción contra el injusto detentador.

En contraposición, se encuentra la teoría recién expuesta, la cual relaciona de manera armónica los artículos 896 y 915 CC. El problema es que "la correcta aplicación del Art. $915 \mathrm{CC}^{\prime \prime 27}$, deja fuera situaciones que no encuentran solución sino mediante la acción contra el injusto detentador.

Una alternativa diversa a la recién mencionada es la acción de precario, regulada en el inciso $2^{\circ}$ del Art. 2195 CC. A grandes rasgos, esta acción está dirigida en contra de un sujeto que detenta materialmente una cosa ajena sin contrato, por ignorancia o mera tolerancia del dueño. Con una opción como esta, cabe preguntarse ¿por qué se ha ampliado el ámbito de aplicación del Art. 915 CC?

Una respuesta contundente otorga Daniel Peñailillo Arévalo, quien al referirse a la acción de precario señala que "su aplicación ha ido enfrentando duros obstáculos; así, supone ausencia de contrato, lo que la deja en dudosa aplicación en todos los casos de contratos nulos, resueltos, revocados, con plazo de duración ya cumplido, emanados de persona distinta del dueño, etc." ${ }^{\prime 28}$.

\section{EstAdOS DE LOS INDIVIDUOS FRENTE A UNA COSA}

Frente a una cosa, un individuo puede encontrarse en diversos estados, a saber: dueño, poseedor, mero tenedor y precarista. El dueño vendría a ser la mejor posición existente y el precarista, la más vulnerable. Parece correcto

\footnotetext{
${ }^{26}$ Barrientos, "De los Bienes", cit. nota n. 17, pp. 242 y 243.

27 Opinión personal del autor en base a los argumentos de Javier Barrientos Grandón.

${ }^{28}$ Peñallillo, Los Bienes, cit. nota n. 3, p. 536.
} 
explicar cada una de ellas para demostrar que la asimilación que se hace de la noción poseedor a nombre ajeno con mero tenedor en términos amplios, es un error. Además, gracias a esta clasificación se podrá dilucidar si la noción de injusto detentador a la que se refiere la doctrina y jurisprudencia, es posible circunscribirla en el Art. 915 CC.

El derecho de propiedad se encuentra regulado en el artículo $19 \mathrm{~N}^{\circ} 24$ de la Constitución Política de la República (en adelante CPR) y los artículos 582 y 583 CC. "El dominio, es el derecho real que se tiene sobre una cosa corporal o incorporal, para usar gozar y disponer de ella según lo resuelva su dueño, sin atentar contra la ley o el derecho ajeno. La propiedad es absoluta, exclusiva, perpetua e inviolable"29. Cabe destacar el reconocimiento del derecho de propiedad sobre las cosas incorporales, es decir, sobre los derechos reales y los derechos personales que emanan del contrato, lo que demuestra la importancia que nuestro ordenamiento jurídico le otorga a este derecho fundamental.

La posesión "es la tenencia de una cosa determinada con ánimo de señor o dueño, sea que el dueño o el que se da por tal tenga la cosa por sí misma o por otra persona que la tenga en lugar y a nombre de él'30. Doctrinariamente se ha discutido si se la debe concebir como un hecho o un derecho, ante lo cual la mayoría considera que es un hecho, aunque la estrecha vinculación ${ }^{31}$ que presenta con el dominio siempre tendrá latente este tipo de interrogantes. De acuerdo a sus elementos se desprende que viene a ser el segundo mejor estado en que un individuo puede encontrarse frente a una cosa, permitiéndole inclusive adquirir el dominio mediante las reglas de la prescripción adquisitiva.

La mera tenencia de acuerdo a los términos del Art. 714 CC, "es la que se ejerce sobre una cosa, no como dueño, sino que en lugar y a nombre del dueño...". De esta definición se desprende que un aspecto fundamental de la mera tenencia es el convencimiento de que la cosa no es propia.

Explicados los conceptos de posesión y mera tenencia, ¿puede asimilarse la noción poseedor a nombre ajeno con mero tenedor? Sus definiciones denotan una diferencia sustancial y ella se refiere a que el mero tenedor reconoce dominio ajeno, mientras que el poseedor no ${ }^{32}$. Los tribunales tienden a sostener su postura, argumentado que la tenencia física de una cosa afecta la posesión

\footnotetext{
${ }^{29}$ Evans de la Cuadra, Enrique, 2004, Los Derechos Constitucionales Tomo III, Editorial Jurídica de Chile, Santiago, 2004, p. 232.

${ }^{30}$ Art. 700 CC.

${ }^{31}$ Peñallillo, Los Bienes, cit. nota n. 3, p. 331.

${ }^{32}$ Salvo los casos del Art. 721 CC, en que un sujeto que posee a nombre ajeno sin ánimo de señor o dueño y retiene indebidamente la cosa, es mero tenedor.
} 
material del dueño, permitiéndole demandar conforme a las reglas de la acción reivindicatoria. Se difiere de esta postura y en general de que sea posible asimilar la noción poseedor a nombre ajeno con mero tenedor ${ }^{33}$. Advertido lo anterior, se deduce que la noción de injusto detentador adoptada por la jurisprudencia mayoritaria no es compatible con la correcta interpretación del Art. 915 CC, por cuanto se utiliza indistintamente con la noción de mero tenedor y concluyendo que poseedor a nombre ajeno no significa mero tenedor (en términos amplios), su acepción como tal genera serias dudas ${ }^{34}$.

Pese a lo anterior, la necesidad de una acción general restitutoria es indudable, por ello se explicará de qué formas la jurisprudencia ha entendido la noción injusto detentador y cuándo es plausible aceptar su aplicación conforme al Art. 915 CC.

Resulta evidente la lejanía de ella respecto del dueño y el poseedor ${ }^{35}$, sobre todo en los inmuebles -ingresados al sistema registral- que se exige para poseer la inscripción en el Conservador de Bienes Raíces. Clarificado lo recién expuesto, el injusto detentador se ha clasificado por la jurisprudencia de las siguientes formas: A. Como un mero tenedor ${ }^{36}$, cuyo título de tenencia ya no se encuentra vigente. B. Aquel individuo que no reconoce dominio ajeno sobre una cosa y la detenta injustamente. Ejemplo de ello es el promitente comprador a quien le entregan anticipadamente una cosa corporal y no celebra el contrato prometido. Cabe destacar que la promesa no es un título que justifique la tenencia, más bien es el contrato prometido el que acredita la tenencia o posesión, según el contrato que se trate. C. Aquel individuo que sin mediar contrato o título alguno detenta una cosa. D. Aquel individuo que justifica la tenencia de una cosa por un contrato emanado de terceras personas (las letras C y D se explicarán a continuación y en el capítulo "casos prácticos", respectivamente).

Por último, se encuentra el precarista, quien conforme al inciso $2^{\circ}$ del Art. 2195 CC, tiene la tenencia de una cosa ajena por ignorancia o mera tolerancia del dueño y carece de un título o contrato que lo justifique a retener la cosa. La doctrina ha definido el precario de diversas formas, para Ramón Meza Barros es "el goce gratuito de una cosa ajena, sin ningún título que lo legitime, tole-

\footnotetext{
33 cit. nota n. 32.

${ }^{34} \mathrm{Al}$ igual que la acción que emana del Art. 915 CC en su concepción amplia.

${ }^{35}$ Salvo la teoría de la "posesión material" y la excepcionalísima regla del Art. 721 CC en caso que se posea a nombre ajeno con ánimo de señor o dueño (situación posible únicamente respecto de cosas corporales muebles).

${ }^{36}$ Debido a que la jurisprudencia ha justificado mayoritariamente la acción contra el injusto detentador en contratos en que una de las partes reconoce dominio ajeno.
} 
rado por el dueño o que se verifica por ignorancia suya ${ }^{\prime \prime 37}$, mientras que para Halabí y Saffirio, el precario "es una situación de hecho en que una persona, denominada precarista, goza de una cosa singular y determinada, mueble o raíz, sin previo contrato y por ignorancia o mera tolerancia del dueño ${ }^{\prime \prime 38}$. Si bien ambas definiciones son coherentes entre sí, la segunda entiende derechamente al precario como una situación de hecho, reforzando la idea de que el precario es un estado del individuo frente a una cosa.

Es importante destacar que "el autor de nuestro Código se preocupó de hacer notar la naturaleza jurídica singular de la figura que describe el inciso segundo del artículo 2195, consignando que en este caso la tenencia es sin previo contrato. De este modo resalta la principal diferencia que hay entre ella y el precario nacido de un contrato ${ }^{\prime \prime 39}$. En esta misma opinión, René Ramos Pazos, quien al referirse al precario señala lo siguiente: "...no hay comodato precario, porque no hay contrato, hay simplemente una cuestión de hecho que es mejor llamar precario ${ }^{\prime \prime 40}$. Pese a ello, buena parte de la doctrina no considera al precario como un estado del individuo frente a una cosa, ello en atención a que no se hace la distinción del comodato precario, el cual es radicalmente distinto, debido a que en éste siempre existe un contrato, pero se presenta alguna de las siguientes situaciones: A. Se estipula que se podrá pedir la restitución de la cosa en cualquier momento; B. No se fija época para la restitución de la cosa; C. No se presta la cosa para un servicio determinado.

Explicado lo anterior, ipuede el afectado proceder en contra del precarista conforme al Art. 915 CC? La respuesta es negativa, en cuanto la inexistencia de contrato entre las partes es exclusiva de la acción de precario, inclusive cuando se presente un contrato que emane de terceros ${ }^{41}$.

Conforme a lo expuesto en los párrafos precedentes, se denota que la noción injusto detentador es sumamente amplia, abarcando variadas situaciones, por ello lo importante es determinar en qué casos puede entenderse incluida en el Art. 915 CC. De acuerdo al análisis realizado, se llega a la conclusión que la noción de injusto detentador que debería ser aceptada por las dificultades que implicaría la restitución del bien en una eventual controversia, se

\footnotetext{
${ }^{37}$ Meza Barros, Ramón, Manual de Derecho Civil, De la Fuente de las Obligaciones, Tomo II, Colección manuales jurídicos N 40, Editorial Jurídica de Chile, Santiago, 1975.

${ }^{38}$ Halabí Riffo, Fuad; SafFirio Suárez, Carlos, La Acción de Precario ante La Doctrina y La Jurisprudencia, Editorial Jurídica Conosur, Santiago, 1996, p. 11.

${ }^{39}$ Halabí; Saffirio, La Acción, cit. nota n. 38, p. 10.

${ }^{40}$ Ramos Pazos, René, "Del Precario", Revista de Derecho Universidad de Concepción Nº 180, 1986, p. 8; quien a su vez hace referencia a Ramos PASCUAL, Graciela, Comodato Precario y Precario, Memoria de Prueba, Concepción, 1982, p. 2.

${ }^{41}$ Se explicará en el capítulo titulado "casos prácticos".
} 
refiere a la del individuo amparado en un contrato o relación jurídica que lo vincula con el dueño -siempre que la acción personal no prospere- y que por alguna circunstancia retiene la cosa injustamente.

El autor es consciente de que en términos estrictos, el sujeto pasivo del Art. 915 CC sería aquel que retiene indebidamente una cosa conforme a la teoría de Javier Barrientos Grandón ${ }^{42}$. El problema es que la acción contra el injusto detentador (reflejado como mero tenedor y/o simple detentador) se encuentra consagrada en nuestra jurisprudencia, por ello parece poco realista intentar prohibir su uso general, aunque ello no obsta restringirla sólo para aquellos casos en que las demás acciones resulten ineficaces.

\section{Consecuencias de neGar la acción CONTRA EL INJUSTO DETENTADOR}

Dejando de lado la discusión de si es correcta o no la postura mayoritaria de nuestra jurisprudencia, es importante preguntarse ¿cuáles son las consecuencias de su rechazo?

Negar esta acción puede significar que el mero tenedor adquiera la cosa corporal conforme a lo dispuesto en la regla $3^{\text {a }}$ del Art. 2510 CC. Se debe recordar que la concepción general, asimila la noción poseedor a nombre ajeno con mero tenedor y el artículo citado faculta que éste, bajo ciertas circunstancias, adquiera el dominio mediante la prescripción adquisitiva extraordinaria. En consecuencia bajo este razonamiento, limitar la acción contra el injusto detentador permitiría que el mero tenedor eventualmente pueda adquirir el dominio.

Si bien este artículo ha sido criticado de manera acérrima por la doctrina, en especial respecto de los inmuebles cuya posesión se pierde o adquiere conforme a las reglas de los artículos 724 y 728 CC, nada impide que los tribunales de justicia apliquen esta regla fundamentándose en su tenor literal.

Clarificado el peligro que supone para el dueño de una cosa la regla $3^{\mathrm{a}}$ del Art. 2510 CC, es menester aclarar que en la actualidad la jurisprudencia tiende a no aceptarlo como una forma de adquirir el dominio. La Corte Suprema con fecha 11 de diciembre de 2007 señaló: "Debe rechazarse la demanda reconvencional de prescripción adquisitiva extraordinaria por el demandado, en la que solicita se reconozca y declare la prescripción adquisitiva extraordinaria del inmueble que ocupa, toda vez que debe tenerse en cuenta que contra título inscrito no es procedente la prescripción ordinaria ni extraordinaria, sino en virtud de otro título inscrito, de conformidad a lo dispuesto en el artículo 2505 del Código Civil; y existiendo de parte del actor

${ }^{42}$ Derribando el sustento de la acción contra el injusto detentador concebida de manera irrestricta, limitando el Art. 915 CC sólo para los casos descritos en el Art. 721 del mismo cuerpo legal. Véase: Barrientos, "De los Bienes", cit. nota n. 17, pp. 242 y ss. 
principal un título inscrito que ampara su derecho de dominio, careciendo por su parte el demandante reconvencional de título inscrito sobre dicho bien raíz, corresponde el rechazo de la pretensión ${ }^{\prime \prime 43}$. Con lo anterior se puede afirmar que el mero tenedor no tendría grandes posibilidades de adquirir el dominio conforme este medio, el problema es que ello no es el punto central de la discordia. En efecto, aunque no pueda adquirir el dominio, todavía queda la interrogante de cómo recuperar el inmueble. Por esta razón, en la eventualidad de restringir la acción contra el injusto detentador, se llegaría al absurdo de conferir al mero tenedor un "dominio práctico" de la cosa, en cuanto el dueño estaría imposibilitado de recuperarla.

En conclusión, se denota la gravedad de negar la acción contra el injusto detentador, aunque como se explicará en las páginas siguientes, existe una serie de mecanismos que permiten al afectado recuperar la cosa, salvo contadas excepciones en que sólo resulta factible accionar conforme a ella.

\section{CASOS PRÁCTICOS}

Resulta interesante disipar la siguiente interrogante: ¿ifrente a qué casos procede o resulta aplicable la acción contra el injusto detentador? Dado lo amplio de las críticas que ha sufrido la acción de precario ${ }^{44}$, la referida acción podría aplicarse a variadas situaciones ${ }^{45}$. El problema es que la jurisprudencia no es unánime en lo relativo a las limitaciones que presenta la acción de precario. "La Corte de Apelaciones de San Miguel en un caso y la Corte Suprema en el otro resuelven que el título invocado por el mero tenedor -un contrato de promesa celebrado con el anterior propietario del predio-, un tercero ajeno al juicio, no es vinculante para el actual propietario y, por lo tanto, no constituye justificación de la ocupación del inmueble frente al actor que excluya la tenencia precaria"/46.

Frente a esta postura, si el contrato emana de un tercero la acción de precario será fructífera. Si bien este tema no está zanjado, es razonable inclinarse por esta posición. Por lo tanto, para que el contrato que se pretenda utilizar como

\footnotetext{
${ }^{43}$ Sentencia de la Excma. Corte Suprema, acoge recurso de casación en el fondo interpuesto en contra de la resolución del tribunal a quo que acogió la demanda reconvencional fundamentada en la regla $3^{\text {a }}$ del Art. 2510 CC, 11 de diciembre de 2007. En: http://www.microjuris.cl [visitado el 04/10/2010], NN Identificador Documento: MJJ16360.

${ }^{44}$ Debido a estas críticas, podría pensarse que la acción de precario procede únicamente en situaciones de inexistencia contractual.

${ }^{45}$ Todas aquellas en que la acción de precario sea de dudosa aplicación (contratos nulos, emanados de tercera persona, etc.).

${ }^{46}$ De La Maza Gazmurı, Iñigo, "Contratos Especiales", Revista Chilena de Derecho Privado No 3, 2004, p. 178.
} 
salvaguarda por el injusto detentador, "resulte oponible al verdadero dueño" ${ }^{147}$, debe necesariamente estar suscrito por ellos, dejando fuera contratos que provengan de terceras personas. La Corte Suprema en sentencia de fecha 01 de agosto de 2007, siguiendo esta postura, dispuso: "En la demanda de precario la suscripción de un contrato de promesa de compraventa, con el anterior dueño del inmueble no constituye título suficiente que pueda esgrimirse respecto del actual propietario del bien, precisamente por el efecto relativo de los contratos, que no pueden oponerse a los terceros que no son parte en los mismos, debiendo concluirse que el demandado no ha justificado la ocupación del inmueble con un título suficiente correspondiendo acoger la demanda incoada ${ }^{\prime \prime 48}$.

Gracias a esta interpretación, se elimina del ámbito de aplicación del Art. 915 CC a todo individuo que posea un título justificativo proveniente de terceras personas, utilizando para dichos casos la acción de precario contenida en el inciso $2^{\circ}$ del Art. 2195 del mismo cuerpo legal, que además tiene el beneficio de tramitarse conforme a las reglas del procedimiento sumario ${ }^{49}$. Entonces, descartado lo anterior, resulta imperante hacerse cargo de los contratos o relaciones jurídicas que emanan de las partes y en que una de ellas se convierte en un injusto detentador. Un ejemplo sería el mencionado al principio de este trabajo, en lo referente al promitente vendedor que entrega el inmueble antes de celebrar el contrato prometido y este nunca se celebra o si entregándolo anticipadamente la promesa caduca ${ }^{50}$. Si bien, existe la acción personal a efectos de exigir la celebración del contrato prometido, podría no tener éxito o el injusto detentador carecer de bienes suficientes para cumplir su obligación, aunque se celebre el contrato a su nombre. Frente a ello, ¿cómo logramos recuperar el inmueble?

La querella de amparo, regulada en los artículos 916 y 921 CC, resulta una alternativa viable. Para que opere resulta indispensable que el actor sea poseedor de la cosa, el objeto debe ser un inmueble o derechos reales constituidos en ellos y debe interponerse en tiempo oportuno ${ }^{51}$. En el caso en comento, el promitente vendedor cumple dichos requisitos, el único inconveniente es el plazo que establece el Art. 920 CC, que lo limita a un año contado desde el acto de molestia o embarazo. Entonces, frente al caso planteado y suponiendo que el

\footnotetext{
${ }^{47}$ De La Maza, "Contratos", cit. nota n. 46, p. 180.

${ }^{48}$ Sentencia de la Excma. Corte Suprema, acoge recurso de casación en el fondo interpuesto en contra de la resolución del tribunal a quo que rechazó la acción de precario, 01 de agosto de 2007. En: http://www.microjuris.cl [visitado el 04/10/2010], № Identificador Documento: MJJ11060.

${ }^{49}$ Art. 680 N ${ }^{\circ} 6$ del Código de Procedimiento Civil.

${ }^{50}$ Ello, en caso de aceptar que el plazo a que se refiere el № 3 del Art. 1554 CC, pueda ser extintivo.

${ }^{51}$ PeÑallillo, Los Bienes, cit. nota n. 3, pp. 547-550.
} 
afectado se encuentra dentro de plazo, podría interponer la querella de amparo, ello en razón que aún no ha pedido la posesión ${ }^{52}$, el objeto es un inmueble y el promitente comprador estaría turbando su posesión ${ }^{53}$.

Ahora, ¿qué ocurre si transcurre el plazo que establece el Art. 920 CC sin impetrar el afectado la querella de amparo? Frente a esta situación, la acción contra el injusto detentador vendría a ser una opción real para poder recuperar el inmueble. En efecto, puede no prosperar la acción de precario por existir un contrato entre las partes ${ }^{54}$, no procede la acción reivindicatoria debido a que no se ha perdido la posesión, no resulta factible interponer la querella de amparo por haber transcurrido el plazo de un año, no procede la querella de restitución ya que no se ha perdido la posesión y tampoco procede la querella de restablecimiento ya que no fue despojado violentamente de la mera tenencia. En la eventualidad que proceda la acción criminal por delito de usurpación ${ }^{55}$, ella impone una multa, mas no la obligación de restituir el inmueble. Por último, el afectado podría también, dentro del plazo de 30 días, interponer un Recurso de Protección fundado en los artículos 19 N² 24 y 20 CPR, el problema es que dicho plazo es sumamente breve y es muy probable que el recurso aludido no se alcance a interponer de manera oportuna.

\footnotetext{
${ }^{52}$ En atención a lo dispuesto en los artículos 724 y 728 CC. Es menester aclarar que es discutible, dependiendo de la acepción que se tenga del valor de la inscripción conservatoria. A este respecto la doctrina se encuentra dividida en dos grandes posturas, a saber: 1. La inscripción-ficción: concibe la inscripción registral en términos absolutos y excluyentes, en consecuencia, no podría considerarse poseedor aquella persona que detenta materialmente un bien raíz con ánimo de señor o dueño, mientras dicho bien no se encuentre inscrito a su nombre. En este caso, el afectado podría interponer una querella de amparo -ver nota 53- (véase: Trucco, Humberto, "Teoría de la posesión inscrita, dentro del Código Civil chileno", Revista de Derecho y Jurisprudencia, Tomo VII, primera parte, 1910, pp. 131 y Ss.; LIRA LIRA, Alejandro, El Régimen de la Inscripción Conservatoria, Alegato, Imp. Talleres de Prisiones, Santiago, 1927, y LaGos LaGos, Moisés, "Consideraciones sobre la posesión y, especialmente, sobre la de los bienes raíces", Revista de Derecho y Jurisprudencia, Tomo XXIII, primera parte, 1926, pp. 117 y ss.); 2. La inscripción-garantía: concibe la inscripción registral sólo como una garantía, en consecuencia se atribuye la calidad de poseedor a quien detenta materialmente un bien raíz -sin inscripción a su nombre- con ánimo de señor o dueño, en cuyo caso procedería derechamente la acción reivindicatoria por parte del afectado (véase: URRUTIA, Leopoldo, "Vulgarización sobre la posesión ante el Código Civil chileno", Revista de Derecho y Jurisprudencia, Tomo XXXI, primera parte, 1934, p. 5, DÁVILA IZQUIERDO, Oscar, Posesión y Prescripción de Inmuebles Inscritos, Imprenta Cervantes, Santiago, 1928).

${ }^{53}$ La tenencia material de un inmueble por parte de un tercero distinto de la persona a cuyo nombre se encuentra inscrita la propiedad, no afecta la posesión inscrita (conforme a lo dispuesto en los artículos 724 y 728 CC), pero sí puede considerarse una turbación que faculta el ejercicio del interdicto posesorio en comento. En apoyo a lo recién expuesto: C.S., R., T. 52, sec. $1^{a}$. p. 294; C.S., G. 1946, $2^{\circ}$ sem., № 34, p. 198; C.S., F. del M. No 236, sent. 2a, p. 160; C.S, F. del M. No 202, sent. 6a, p. 176.

${ }^{54} \mathrm{Si}$ el contrato emana de las partes, el promitente comprador tendría un título que lo ampara (es discutible) pudiendo el tribunal rechazar la acción de precario.

${ }^{55}$ Artículos 457 y 458 del Código Penal.
} 
Agotadas todas las opciones señaladas en el párrafo anterior y suponiendo que la acción personal tampoco fuera efectiva, sería el momento de utilizar la acción contra el injusto detentador. Sólo en esta eventualidad, resulta "entendible y aceptable ${ }^{\prime \prime 56}$ el ejercicio de esta acción.

Cabe destacar que en caso alguno puede estimarse que esta acción se encuentre justificada en base a normas legales, pero sí suple un vacío que se genera por la concepción que tiene el Código Civil chileno, respecto del valor absoluto que se le otorga a la inscripción registral. Recapitulando, para la jurisprudencia mayoritaria la acción que emana del Art. 915 CC, vendría a ser una suerte de acción reivindicatoria excepcional que se permite contra el injusto detentador, pero que en realidad hace las veces de una acción general restitutoria frente a determinadas situaciones que no permiten otra solución.

Del caso analizado, se concluye que la acción contra el injusto detentador procedería $\mathrm{a}^{57}$ toda vez que exista un contrato o relación jurídica entre las partes ${ }^{58}$, quien detente la cosa lo haga injustamente, la acción personal que corresponda no prospere ${ }^{59} \mathrm{y}$ haya transcurrido el plazo para demandar el interdicto posesorio correspondiente ${ }^{60}$.

Cumplidos los requisitos recién expuestos, una lista más o menos completa de casos sería la siguiente, a saber:

1. Promitente comprador a quien le entregan anticipadamente una cosa corporal y no celebra el contrato prometido u ocurrido esto, la promesa caduca ${ }^{61}$;

2. Comodatario que se niega a restituir la cosa corporal;

3. Arrendatario que se niega a restituir la cosa corporal;

\footnotetext{
${ }^{56}$ Opinión personal del autor, en base a la necesidad de contar con una acción general restitutoria.

${ }^{57} \mathrm{Si}$ bien el autor adhiere a la teoría propuesta por Javier Barrientos Grandón (BARRIENTOS, "De los Bienes", cit. nota n. 17, pp. 242 y ss.), es prudente concederla en aquellos casos en que las demás acciones no otorguen solución.

${ }^{58}$ En caso de que el contrato no conste por escrito, el injusto detentador difícilmente podrá probar la existencia de un título que justifique su tenencia, pudiendo el demandante optar por el precario.

${ }^{59}$ Si bien es discutible la necesidad de accionar primero mediante la acción personal que corresponda, se está por esa postura en el afán de restringir la acción contra el injusto detentador, por cuanto la aplicación del Art. 915 CC fuera de los casos del Art. 721 del mismo cuerpo legal, debe ser excepcional. Además, el tribunal podría abstenerse de conocer, argumentando que existe una acción específica para perseguir la restitución de la cosa, de igual forma podría defenderse la contraparte. Por ejemplo, en caso de tratarse de un arrendamiento de inmueble urbano, rige la Ley $N^{\circ} 18.101$, de 1982, que viene a ser ley especial y prefiere a las normas generales conforme al Art. 13 CC. Respecto del comodato, el Art. 2180 CC prevalece sobre el Art. 915 del mismo cuerpo legal. En el mismo sentido, en el contrato de depósito el Art. 2228 CC prevalece sobre el Art. 915 CC. De igual forma en la promesa, el Art. 1554 CC prima sobre el Art. 915 CC.

${ }^{60}$ En caso de tratarse de cosas corporales muebles, debe obviarse este requisito, pues las acciones posesorias no proceden respecto de ellas.

${ }^{61}$ Que corresponde al caso explicado acuciosamente en las páginas anteriores de este trabajo.
} 
4. Depositario que se niega a restituir la cosa corporal mueble;

5. El secuestre que se niega a restituir la cosa corporal;

6. Usufructuario que una vez transcurrido el plazo o cumplida la condición, se niega a restituir la cosa corporal;

7. Aquel beneficiado de un derecho de uso o habitación que una vez transcurrido el plazo o cumplida la condición, se niega a restituir la cosa corporal;

8 . Acreedor prendario que se niega a restituir la cosa corporal mueble, una vez satisfecho el crédito.

En los tres casos que se expondrán a continuación, no se deben cumplir los requisitos recién enunciados, ya que son los únicos casos reales de un poseedor a nombre ajeno en los términos del Código Civil. Estos son:

9. El mandatario que posee a nombre ajeno y retiene indebidamente una cosa corporal;

10. El representante legal que posee a nombre ajeno y retiene indebidamente una cosa corporal, y

11. El agente oficioso que posee a nombre ajeno (con conocimiento y aceptación del interesado) y retiene indebidamente una cosa corporal.

De la enumeración expuesta resalta lo siguiente: A. La acción del Art. 915 CC procede respecto de cosas muebles e inmuebles ${ }^{62}$, haciendo la salvedad que al no existir un sistema registral en los primeros, la prueba del que se dice dueño resultará muy difícil en caso de que el contrato no conste por escrito ${ }^{63}$. B. La mayoría de los casos son contratos y relaciones jurídicas que reconocen dominio ajeno (arrendamiento, comodato, depósito, secuestro, uso, habitación, usufructo y prenda), por ende, de acuerdo a la correcta doctrina, no procedería la acción contra el injusto detentador. C. En lo que respecta al mandatario, representante legal y agente oficioso, se refuerza la idea de que son los únicos casos efectivos $^{64}$ de un poseedor a nombre ajeno ya sea con o sin ánimo de señor o dueño. D. Si bien, son numerosos los casos, sólo el referido a la promesa tiene mala perspectiva frente a la acción personal, los demás probablemente jamás pasarían de esa instancia. E. Aunque en todos los casos explicados se necesita una acción que garantice la restitución de la cosa, se infiere que la aplicación efectiva que debiera tener la acción contra el injusto detentador es mínima, gracias a las demás acciones conferidas. F. Entonces, los tribunales de justicia admiten apresuradamente esta acción, por cuanto basta ser dueño de la cosa para que sea aceptada a tramitación.

\footnotetext{
${ }^{62}$ En el contrato de depósito y la prenda, sólo procede respecto de cosas corporales muebles.

${ }^{63}$ Salvo el contrato de promesa, que de acuerdo al № 1 del Art. 1554 CC es solemne y debe constar por escrito.

${ }^{64}$ El Código Civil así lo reconoce en su Art. 721.
} 
Esta selección de casos aclarará cuándo se aplica correctamente la acción contra el injusto detentador ${ }^{65}$. Ergo, todo caso que no se circunscriba dentro de los requisitos mencionados, no debe ser tramitado conforme al Art. 915 CC, por cuanto la acción de precario, querella de amparo, querella de restablecimiento y las acciones personales resultan más adecuadas y justificadas por el mismo cuerpo legal.

Finalmente, es menester destacar que existe una alternativa diversa a la acción contra el injusto detentador. En efecto, en todos aquellos casos en que las acciones tradicionales no resulten aplicables, se podría interponer una "acción innominada de dominio"166 tendiente a obtener la restitución de lo debido, fundamentándola en el artículo 19 № 24 CPR y en el Art. 582 CC. Se apoya lo que propone Daniel Peñailillo Arévalo, más aún teniendo en consideración que el inciso $2^{\circ}$ del Art. 76 CPR consagra el principio de inexcusabilidad de los jueces, incluso a falta de ley. En consecuencia, esta alternativa podría suplir la acción contra el injusto detentador fundada en el Art. 915 CC. Si bien, el autor es consciente de las dificultades que podría presentar la interposición de una acción innominada de dominio, no es menos cierto que aquélla cuenta con fundamento constitucional, por cuanto el Art. $19 \mathrm{~N}^{\circ} 24$ CPR tutela el derecho de propiedad y el inciso $2^{\circ}$ del Art. 76 CPR impide al juez, una vez reclamada su intervención, excusarse de ejercer su autoridad. De esta forma, se dejaría la aplicación del Art. 915 CC para aquellos casos descritos en el Art. 721 del mismo cuerpo legal.

\section{CONCLUSIONES}

El Art. 915 CC ha tenido un desarrollo jurisprudencial no menor, que en los últimos años se ha inclinado por la teoría que lo conceptualiza como una acción reivindicatoria excepcional que procede contra el injusto detentador. Mediante el desarrollo de este artículo, se intentó demostrar que dicha postura no es justificable mediante las normas del Código Civil, pero sí frente a determinadas situaciones que resultan injustas y que nuestras leyes no han sabido enfrentar. En otras palabras, esta acción nace de la urgencia que tienen los tribunales de hacer justicia e impedir abusos.

Resulta interesante destacar lo difícil que es encontrar jurisprudencia a favor de la correcta doctrina del Art. 915 CC, mientras que para las restantes abunda, especialmente la que la concibe como una acción reivindicatoria excepcional. Ello viene a demostrar que la jurisprudencia tiene un valor mucho mayor al que

\footnotetext{
${ }^{65}$ Haciendo la salvedad de que su correcta aplicación, en términos estrictos, es la propuesta por Javier Barrientos Grandón (BarRIENTOS, "De los Bienes", cit. nota n. 17, pp. 242 y ss.). En términos amplios se adhiere a que sea aceptada en los demás casos expuestos una vez cumplidos los requisitos señalados.

${ }^{66}$ Peñallillo, Los Bienes, cit. nota n. 3, p. 537.
} 
generalmente se le suele conferir en la enseñanza común del Derecho, inclusive es posible sostener que en algunos temas -como el tratado aquí- es fuente formal del Derecho. Es evidente que la creación jurisprudencial no se refiere únicamente al Art. 915 CC, existen otras materias en que la jurisprudencia también ha realizado una intensa labor creativa, tales como el precario y el daño moral.

Es importante aclarar que lo expuesto en estas páginas no pretende cambiar la concepción mayoritaria que se tiene respecto de la naturaleza del Art. 915 CC, no por una imposibilidad argumentativa ${ }^{67}$, sino más bien porque dicha concepción es necesaria y lo seguirá siendo mientras no se regule específicamente, sobre ella o se adopte otra solución. Sin embargo, lo anterior no puede significar un uso desmedido de la acción contra el injusto detentador, por ello se mencionaron las diversas acciones con las que puede contar el afectado, específicamente, las acciones personales respectivas, interdictos posesorios, la acción criminal por delito de usurpación, la acción de protección y la acción de precario. Respecto a esta última, se explicó que las limitaciones que se le adjudican no tienen una aceptación uniforme en la jurisprudencia, en consecuencia, es capaz de circunscribir a su respecto una serie de situaciones que en la actualidad se tramitan conforme la acción contra el injusto detentador. Con todo y pese a la no despreciable cantidad de acciones que dispone el afectado, aún existen determinados casos que no encuentran solución mediante ellas, frente a lo cual es perfectamente entendible recurrir a la acción contra el injusto detentador.

Pese a lo anterior, surge la interrogante de si realmente es necesario desvirtuar el significado literal del Art. 915 CC, especialmente cuando se podría interponer una "acción innominada de dominio"168 con la finalidad de obtener la restitución de la cosa debida. En otras palabras, ¿̇esulta comprensible la adecuación ${ }^{69}$ del Art. 915 CC? ¿no será lo correcto interponer una acción innominada de dominio en todas aquellas situaciones que escapen de las acciones tradicionales? La respuesta a estas interrogantes queda a consideración del lector.

\section{BibLIOGRAFíA}

Alessandri Rodríguez, Arturo; Somarriva Undurraga, Manuel, Curso de Derecho Civil, Tomo II, Editorial Nascimento, Santiago, 1957. , Los Bienes y Los Derechos Reales redactadas, ampliadas y puestas al día por Antonio Vodanovic H., Editorial Nascimento, Santiago, 1974.

\footnotetext{
${ }^{67}$ Por el contrario, existen sólidos argumentos que la rechazan.

${ }^{68}$ Peñallillo, Los Bienes, cit. nota n. 3, p. 537.

${ }^{69}$ En relación a las dos primeras teorías que lo entienden como una acción reivindicatoria excepcional y como una acción restitutoria especial, respectivamente.
} 
Alessandri Rodríguez, Arturo, De Los Bienes, versiones taquigráficas tomadas en la clase del señor Arturo Alessandri Rodríguez por Onias León Gaete, Editorial Zamorano y Caperan, Santiago, 1937.

Barrientos Grandón, Javier, "De los Bienes y de su Dominio, Posesión, Uso y Goce", en Revista Chilena de Derecho Privado N 4, Santiago, 2005. , "De los Bienes y de su Dominio, Posesión, Uso y Goce: Poseedor a Nombre Ajeno", en Revista Chilena de Derecho Privado Nº 8, Santiago, 2007.

Claro Solar, Luis, Explicaciones de Derecho Civil Chileno y Comparado, Tomo IX, Editorial Nascimiento, Santiago, 1935.

DÁvILA IZQUIERDO, Oscar, Posesión y Prescripción de Inmuebles Inscritos, Imprenta Cervantes, Santiago, 1928.

De la Maza Gazmuri, Iñigo, "Contratos Especiales", Revista Chilena de Derecho Privado N³, Santiago, 2004.

Evans de la Cuadra, Enrique, Los Derechos Constitucionales, Tomo III, Editorial Jurídica de Chile, Santiago, 2004.

Halabí Riffo, Fuad; Saffirio Suárez, Carlos, La Acción de Precario ante la Doctrina y la Jurisprudencia, Editorial Jurídica Conosur, Santiago, 1996.

Lagos Lagos, Moisés, "Consideraciones sobre la posesión y, especialmente, sobre la de los bienes raíces", Revista de Derecho y Jurisprudencia, Tomo XXIII, primera parte, Santiago, 1926.

LIRA LIRA, Alejandro, El Régimen de la Inscripción Conservatoria, Alegato, Imp. Talleres de Prisiones, Santiago, 1927.

Messineo, Francesco, Manuale di Diritto Civile e Commerciale, Vol. II, Giuffre, Milán, 1947.

Meza Barros, Ramón, Manual de Derecho Civil, de la fuente de las Obligaciones, Tomo II, Colección manuales jurídicos N 40, Editorial Jurídica de Chile, Santiago, 1975.

Peñallillo Arévalo, Daniel, Los Bienes, la Propiedad y otros Derechos Reales, Editorial Jurídica de Chile, Santiago, 2006.

Ramos Pascual, Graciela, Comodato Precario y Precario, Memoria de Prueba, Concepción, 1982.

Ramos Pazos, René, "Del Precario", Revista de Derecho Universidad de Concepción Nº 180, Concepción, 1986.

Rozas VIAL, Fernando, Los Bienes, Editorial LexisNexis, Santiago, 2006.

Trucco, Humberto, "Teoría de la posesión inscrita, dentro del Código Civil chileno", Revista de Derecho y Jurisprudencia, Tomo VII, primera parte, Santiago, 1910. 
URRUTIA, Leopoldo, "Vulgarización sobre la posesión ante el Código Civil chileno", en Revista de Derecho y Jurisprudencia, Tomo XXXI, primera parte, Santiago, 1934.

Veloso Chávez, Alberto, La Reivindicación, Memoria de Prueba, Santiago, 1947.

\section{NORMAS}

Código Civil de la República de Chile, Editorial Jurídica de Chile, $18^{a}$ edición, Santiago, 2008, artículos: 13, 577, 582, 583, 700, 714, 719, 720, 721, 724, 728, 889, 894, 895, 896, 915, 916, 920, 921, 1554, 2180, 2195, 2215, 2505, 2510.

Código de Procedimiento Civil de la República de Chile, Editorial Jurídica de Chile, $19^{a}$ edición, Santiago, 2008, artículo: 680 № 6.

Código Penal de la República de Chile, Editorial Jurídica de Chile, 24a edición, Santiago, 2010, artículos: 457,458.

Constitución Política de la República de Chile, Editorial Jurídica de Chile, 11a edición, Santiago, 2007, artículos: 19 № 24, 20, 76.

LEY $N^{\circ} 18.101$, fija normas especiales sobre arrendamiento de predios urbanos. Diario Oficial, 29 de enero de 1982.

\section{JURISPRUDENCIA}

En orden de aparición según notas al pie de página.

Montreal y otra con Rosales, Excma. Corte Suprema, 12 de mayo de 1992. En: http://www.microjuris.cl [visitado el 04/10/2010], № de Identificador Documento: RDJ1569.

Hurtado con Comercial Santa Elena S.A., Excma. Corte Suprema, 23 de abril de 2007. En: http://www.microjuris.cl [visitado el 04/10/2010], No de Identificador Documento: MJJ9696.

Fisco de Chile con Kraus, Iltma. Corte de Apelaciones de San Miguel, 25 de septiembre de 2009. En: http://www.microjuris.cl [visitado el 04/10/2010], $N^{\circ}$ de Identificador Documento: MJJ21876.

Silva CON TAPIA, Excma. Corte Suprema, 27 de diciembre de 2004. En: http:// www.microjuris.cl [visitado el 04/10/2010], $N^{\circ}$ de Identificador Documento: MJJ9149.

Silva con TAPIA, Iltma. Corte de Apelaciones de Santiago, 11 de agosto de 2003. En: http://www.poderjudicial.cl [visitado el 04/10/2010], Rol № 78921998. 
InZUNZA CON SALAZAR, Excma. Corte Suprema, 13 de junio de 2007. En: http:// www.poderjudicial.cl [visitado el 04/10/2010], Rol No 5210-2005

Risi con Buenaventura S.A., Excma. Corte Suprema, 11 de diciembre de 2007. En: http://www.microjuris.cl [visitado el 04/10/2010], No Identificador Documento: MJJ16360.

Alfaro con Nahuelcura y otros, Excma. Corte Suprema, 01 de agosto de 2007. En: http://www.microjuris.cl [visitado el 04/10/2010], № Identificador Documento: MJJ11060. 